\title{
GCU
}

Glasgow Caledonian

University

University for the Common Good

\section{Age effects in mortality risk valuation}

Brey, Raul; Pinto Prades, Jose Luis

Published in:

European Journal of Health Economics

DOI:

10.1007/s10198-016-0852-8

Publication date:

2017

Document Version

Author accepted manuscript

Link to publication in ResearchOnline

Citation for published version (Harvard):

Brey, R \& Pinto Prades, JL 2017, 'Age effects in mortality risk valuation', European Journal of Health Economics, vol. 18, no. 7, pp. 921-932. https://doi.org/10.1007/s10198-016-0852-8

\section{General rights}

Copyright and moral rights for the publications made accessible in the public portal are retained by the authors and/or other copyright owners and it is a condition of accessing publications that users recognise and abide by the legal requirements associated with these rights.

Take down policy

If you believe that this document breaches copyright please view our takedown policy at https://edshare.gcu.ac.uk/id/eprint/5179 for details of how to contact us. 


\title{
AGE EFFECTS IN MORTALITY RISK VALUATION
}

Raul Brey (rbresan@upo.es)

Department of Economics, Pablo de Olavide University, Ctra. de Utrera km. 1, 41013 Seville, Spain

Jose Luis Pinto Prades (jlpinto@unav.es)

Department of Economics, University of Navarra, Pamplona, Spain Yunus Centre for Social Business and Health, Glasgow Caledonian University, Glasgow, UK

\begin{abstract}
We provide more evidence on the functional relationship between willingness to pay for risk reductions and age (the senior discount). We overcome many of the limitations of previous literature that has dealt with this issue, namely, the influence of the assumptions used in statistical models on the final results. Given our large sample size $(n=6024)$ we can use models that are very demanding on data. We use parametric (linear, quadratic, dummies), semi-nonparametric and non-parametric models. We also compare the marginal and the total approach and we show that they provide similar results. We also overcome one of the limitations of the total approach, that is, we include the effects of socioeconomic characteristics that are correlated with age (education and income). Our main result is that all these different approaches produce very similar results, namely, they show an inverted-U relation between the Value of a Statistical Life and age. Those results can hardly be attributed to problems of collinearity, omitted variables or statistical assumptions. We find a clear senior discount effect. This effect seems concentrated on those who have lower education and income levels. We also find that the Value of a Statistical Life Year increases with age.
\end{abstract}

\section{Keywords: mortality risk valuation; value of statistical life; seniority effect; willingness to pay}




\section{Introduction}

One of the most relevant concepts in Cost-Benefit Analysis is the Value of a Statistical Life (VSL). The VSL is defined as the marginal relation of substitution between wealth and the risk of death. In practice, it is usually estimated from the amount that a subject is willing to pay (WTP) for a small mortality risk reduction $(\Delta \mathrm{p})$ as $\mathrm{WTP} / \Delta \mathrm{p}$. For example, if a subject is WTP $€ 30$ for a 2 in 100,000 mortality risk reduction, the VSL would be 1.5 million euro ( $€ 30 \times 100,000 / 2)$. One issue that has received considerable debate in the literature on VSL is the so-called "senior discount", that is, whether VSL should be age-related, more specifically, would different (lower) VSL be applied to older people? This also has very important consequences over another key concept, namely, the Value of a Statistical Life Year (VSLY).

The value per statistical life year (VSLY) is an approach for adjusting VSL estimates to reflect differences in remaining life expectancy. In some cases, researchers simply estimate the VSLY dividing the VSL by the discounted expected number of life-years remaining for the average individual studied. That is, they assume that the VSLY is constant. In this paper, given our large database, we do not use such restrictive assumption since we estimate age-specific values of VSL. To estimate VSLY, we have annuitized age-specific VSLs based on age-specific years of life expectancy and we obtain age-specific VSLY values.

In many areas, like air pollution or health care, where most of the benefits fall on old people, the VSLY could be even a more relevant concept than the VSL. In fact, in the economic evaluation of medical technologies life years (or Quality-adjusted life years QALYs-) are more often used as a measure of benefit than lives. Traditionally, many regulations have used the same VSL regardless of age and a constant VSLY. However, if VSL does not depend on age, life years of those with lower life expectancy (usually old people) receive higher values than those with higher life expectancy (usually young people). It is then quite relevant to have clear evidence of the existence or not of the "senior discount" and its implications for policy. This paper aims at shedding more light into the debate over the existence of the senior discount. 
Viscusi [25] suggests that the existence or not of a senior discount should be based on individual's willingness to pay for risk reduction. However, Crooper, Hammit and Robinson [8] indicate that "few studies provide a clear test of the effect of age on VSL". They point out to statistical problems encountered in many studies, like imposing a certain functional form (linear or quadratic) and they suggest that more flexible functional forms are needed. Kriström [13] and McFadden [16, 17], among others, emphasize the limitations of the parametric approach since the statistical assumptions on the response probability function are quite demanding and erroneous assumptions may lead to a remarkable bias in the estimation of the welfare measure. In the context of mortality risk valuation, Alberini [1] finds that the age effects in mortality risk valuation are not robust to researchers' choices about these assumptions. Krupnick [14] emphazises that most studies focus on the marginal effect of age but not on the total effect. The marginal effect approach tries to estimate the relationship between age and WTP, holding (theoretically) other variables constant. However, there are important issues of collinearity (age is a proxy for other variables) and omitted variables, within this approach. Krupnick [14] suggests that some of these issues can be handled under the total effect approach. Here, age is treated as a proxy for variables that change with age. We estimate total effect dividing the sample into different age groups and comparing WTP between those groups. Very few papers supplement the marginal analysis with total effect analysis probably because it is necessary to have a large sample size with enough seniors in order to implement this approach. The problem of the total approach is that we do not know if any senior effect is related to age per se or to some characteristics that are age-related unless the analysis is conducted in subgroups of similar characteristics. However, this requires a very large sample size since some groups (e.g. old people with high education and high income) quickly become too small.

Our study overcomes most of these problems given the large sample size $(n=6024)$ we have. First, we estimate both marginal and total effects. We are not aware of any other paper that has combined the two approaches. Second, within marginal effect we use several specifications of the age variable, namely, we use linear, quadratic, dummies and semi-nonparametric. We use the semi-nonparametric specifications proposed by Alberini [1] since she showed that they may generate very different (and opposite) results to those obtained from parametric techniques. Our results are robust to those 
different specifications. Third, we used non-parametric methods in order to apply total effect analysis. In this way, we can overcome the problems of collinearity and omitted variables that can influence the results of the marginal approach (Krupnick [14]) and results are not influenced by the assumptions used in the statistical models. We estimate WTP within groups that are homogeneous not only in terms of age but also in income and education. In this way, the total effect analysis conducted in this paper overcomes one of the problems of this approach, namely, that it does not disentangle the effect of different variables that are correlated with age. We can also make a distinction between age groups that they all fall within the concept of "senior", that is, those who are “younger" seniors (say 60-75 years old) and older seniors (more than 75). There is very little evidence in the literature between WTP within senior age groups. Finally, following Viscusi and Hersch [26] we also estimate the relationship between the value of a statistical life year (VSLY) and age. In summary, the main contribution of this paper is to calculate age-specific values for VSL using techniques that avoid the main biases that, according to the literature, could affect previous calculations.

The main result that we obtain is that all these different approaches (parametric, semiparametric, non-parametric, marginal and total effects) produce very similar results and it confirms previous evidence, namely, the relationship between VSL and age is inverse U-shaped. Those results can hardly be attributed to problems of collinearity, omitted variables or statistical assumptions. We find a clear senior discount effect. This effect seems concentrated on seniors who have lower education and income levels and on older seniors. We also find that VSLY increases with age specially above 65 .

Our paper proceeds as follows. First we describe the structure of the survey. Second, we justify the quality of our data, applying some validity tests. Krupnick mentions as validity tests "that variables expected to affect WTP do in fact have such an effect" (p. 268). However, Loomes [15] also mentions a different kind of validity tests that are the mirror image of those mentioned by Krupnick, namely, that variables that are not expected to affect WTP do not in fact have an effect. One paradigmatic case that variables that are not expected to affect WTP end up influencing WTP is framing effects. We study to what extent framing effects influence our data. We show that our data pass these validity tests. The paper then proceeds to present the main econometric models we use. This is followed by the presentation of the main results, that is, the 
relationship between WTP and Age. We present first the results of the marginal approach, using parametric and semiparametric techniques. We then present the results of the total effect approach using non-parametric techniques. Finally, discussion and conclusions close the paper.

\section{Survey design}

To study the relationship between WTP and Age we estimated individual willingness to pay for reductions in the risk of mortality due to acute myocardial infarction (AMI). We used this case for two reasons. One is that we already had experience with this good since it was used in previous work ([19]). We used the same framing and visual aids that were developed for the former study. The second reason is that, in the former study, we observed that subjects did not need very long explanations of the nature of an AMI and its consequences. Most people are familiar enough with the concept of AMI so a short explanation is enough for them to understand the health problem we are dealing with. We thought that we could use a simpler questionnaire in this case than in [19]. The questionnaire we used for the present survey was included in a general survey that was conducted by ASEP (http://www.jdsurvey.net), a private consulting firm that carried out every month from 1986 to 2011 a survey on "Spaniards' Public Opinion". It was a Personal Face to Face survey, representative of the Spanish population 18 years and over. Sample size was 1200 subjects each month. It is a stratified random sample. The strata are 1) the Autonomous Regions and 2) Municipalities grouped by population size. There is a random selection of municipalities and electoral districts within each municipal stratum and Autonomous Community. Household selection is conducted through random route procedures within each electoral district. Final selection of respondent in each household is based on gender and age quotas or on Kish's Tables. We inserted our survey in five of their waves (December 2005, February, March, April and May 2006) for a total sample size of 6024 subjects.

The first part of the text was aimed at explaining what an AMI is and the concept of risk of mortality linked to it. It was explained that after an AMI some people die immediately and some other people survive. However, in the most acute cases, the heart of those people who survive is damaged and they need to take medicines. In spite of taking these medicines (medicine $\mathrm{X}$ in the survey), 17\% of these people die the first year after the heart attack. After this first year, only a very few people die from the 
damage caused by an AMI. The data were obtained from Randomized Controlled Trials [20]. The status quo was then to take medicine X, pay nothing and accept a $17 \%$ risk of death the first year after the AMI.

The second part was devoted to the preference elicitation questions. Subjects were asked to assume that a new medicine (medicine A) was introduced providing a lower mortality risk. A visual aid was included to help respondents to understand better the risk reduction provided by the medicine. The treatment had to be followed for one year after the AMI.

We used three different elicitation procedures in order to test for the influence of framing effects. Each survey was divided in 6 groups of about 200 subjects each. We then have a total of 30 different subgroups ( 5 waves x 6 subsamples in each wave) divided as follows:

A. Elicitation Procedure 1 (EP1): Double-bound Contingent Valuation. Groups 1 to 12 (December and February surveys). Each subject was asked if s/he would be willing to pay or not a certain amount of money (initial bid) monthly, for one year, in order to take medicine $\mathrm{A}$, which would reduce the risk of death by $3 \%$ (from 170 in 1000 to 140 in 1000) the first year after the AMI. If s/he accepted this amount next bid was higher, otherwise lower. An "I do not know" answer was also allowed. The distribution of bids by group can be seen in Table I.

B. Elicitation Procedure 2 (EP2): Groups 13 to 20 (the six Groups of March and two Groups of April) were allocated to this procedure. In this case, subjects were told that the effect of medicine A could be high (final risk Q) or low (final risk $\mathrm{R}, \mathrm{Q}<\mathrm{R}$ ) depending on patient's characteristics and that there was a medical test that could tell them if they were in one group or another. They were also told that the cost of the medicine was not certain and it could also be high (Y€) or low $(Z €)$. They were asked four questions depending of the different combinations of effectiveness (high-low) and cost (high-low). For example, they were told "the medical test tells you that you are in group 1. Medicine A will reduce your risk from 170 in 1000 to $Q$. The cost for you is Z€”. This represents the high(effectiveness)-low(price) combination. Then, three more questions were asked using combinations high-low, low-high and low-low. In summary, the subject had to make four binary choices. An "I do not know" answer was 
also allowed. The options that the subjects had to compare to the status quo ( $17 \%$ of risk, no cost) can be seen in Table I.

C. Elicitation procedure 3 (EP3): This group was very similar to EP2 since subjects always had to do four binary choices. However, in this case, all options had the same price and they were different in term of the risk reduction. That is, they were told that the effect of the medicine was not certain and that it worked differently in four groups of patients. While initial risk was always 170 out of 1000 final risk could take four different values. Again, the question was "the medical test tells you that you are in group 1. Medicine A will reduce your risk from 170 in 1000 to $Q$. The cost for you is $Z €$ ". The cost $(Z €)$ was always constant. In practice, they had to say in which cases they would pay $Z €$ and in which cases they would not. An "I do not know" answer was also allowed. The options that the subjects had to compare to the status quo can be seen in Table I.

This design makes possible to conduct several tests about the quality of the data in line with the suggestions of Krupnick [14] and Loomes [15], that is, responses should be sensitive to theoretically relevant factors and insensitive to theoretically irrelevant factors. One different between our setting and other settings used in the literature on the value of a statistical life, is that the risk reduction we use is significantly larger than other studies that have used very small risk reductions (e.g. 1 in 100.000 or in 10.000). One problem of this is that our estimations of VSL cannot be directly compared to the value of VSL estimated in those settings. However, the main objective of this paper is not to estimate VSL but the relationship between VSL and age and this can be done using a $3 \%$ risk reduction, as it is our case. Apart from that, the use of larger risk reductions may have some advantages, since there is evidence that subjects have problems in working with very low probabilities. In any case, we believe it is important to use risk reductions that correspond to the health setting in order to obtain conclusions that are relevant in the allocation of health care resources.

\subsection{Sensitivity to theoretically irrelevant factors}

Three kinds of effects are analysed here:

1. Framing effects: we test if WTP depends on the elicitation procedure used in our experiment. In order to do this, we compare the probability of accepting a bid for a 3\% risk reduction in EP1 with the probability of accepting the same bid for 
the same risk reduction in EP2 and EP3. Since the first response to the DBDC is, theoretically, the most unbiased one we compare the probability of accepting the first bid in EP1 with the probability of accepting the same bid in EP2 and EP3.

2. Ranking effects: we test if WTP depends on the position (best, intermediate, worst) of the alternative within the choice set. According to Parducci's RangeFrequence model [18] the perceived utility of an object depends on its ranking within a context. For example, in subgroup 13 the alternative (3\% risk reduction, $240 €$ ) was the worse deal in the choice set (it provided the smallest risk reduction at the highest price) while in subgroup 16 it was the best alternative in the choice set (highest risk reduction at the lowest price). According to Parducci's model the probability of choosing this alternative against the status quo should have been higher in 16 than in group 13. That is, the higher the position in the rank of the choice set the higher the probability of choosing this alternative against the status quo.

3. Probability framing: Within EP1 we tested if the numerical way of presenting the data had some influence. While in most of the cases risks were presented as $\mathrm{X}$ out of 1000, in some groups (6 and 12) we used percentages (X out of 100). This is the difference between groups 3 and 6 and between 9 and 12 .

4. Order effects: within EP3 we tested the existence of order effects. This was done comparing groups 21 vs 22 and 23 vs 24 . The questions were the same in groups 21-22 and in groups 23-24. In groups 21 and 23 subjects started with the smallest risk reduction and were progressively shown higher risk reductions. In groups 22 and 24 the order was reversed.

\subsection{Sensitivity to theoretically relevant factors}

Two kinds of effects are analysed here:

1. We analyse the sensitivity of responses to the size of the good, in our case, risk reduction. The existence of scope effects is tested comparing the results of elicitation procedures 1 and 3 (EP1 and EP3). We do not use EP2 since we do not have enough variability in the levels of risk reduction analysed and we cannot estimate survival curve reliably. The response probability function was estimated using the bids that are common to EP1 and EP3, that is, $30 €, 90 €$, $240 €, 720 €$ and $1500 €$. Scope effects will be estimated comparing the mean WTP for a 3\% risk reduction in EP1 with the corresponding mean WTP for 
smaller risk reductions in EP3. We can also conduct a further consistency test, that is, we can test if WTP for the same risk reduction (3\%) is similar in both groups.

2. We analyse if WTP changes in the predicted direction with personal characteristics such as income.

It can be seen that the design is very demanding in relation to the consistency checks we can conduct. We thought that it was very important that we could show that our data were consistent. One reason is that since our survey was a shorter version of the more in depth survey we conducted previously, we had to be sure that the quality of the data was good. It would have been simpler to use the common Double (or Single) Bound Dichotomous Choice format to all cases but we thought we needed more checks on the validity of our data. However, one drawback of using this design is that the number and type of questions asked to subjects was different in each framing. For this reason, in order to study the relationship between WTP and Age we used only one response from each individual, that is, the one corresponding to the $3 \%$ risk reduction from $17 \%$ to $14 \%$. The reason is that this risk reduction was asked to all subjects. For EP1 we use only the response to the first bid. For EP3 we only have one observation for the $3 \%$ risk reduction so this is the response we use. Finally, in EP2 we have two responses for the 3\% risk reduction. In this case, we only use the response to the first question about a $3 \%$ risk reduction ${ }^{1}$.

\section{Econometric models}

We assume that the subject has to choose between two different scenarios with different levels of risk of death $\left(q_{0}, q_{1}\right)$ and income $\left(\mathrm{Y}, \mathrm{Y}-\mathrm{A}_{\mathrm{k}}\right)$. We consider the amount $A^{*}$ that would make the individual indifferent between both options:

$$
A^{*}=f\left(q_{1}^{0}, q_{1}^{1}, Y, \vec{x}, \varepsilon\right)
$$

\footnotetext{
${ }^{1}$ In order to test how sensitive are our results to this way of analyzing the data we replicate our analysis using only the response to the first bid in the traditional DBDC approach. That is, only the data of two waves (December, February). Similar conclusions were drawn.
} 
where $\vec{x}$ is a vector of respondent's characteristics (including age), and $\varepsilon$ is an stochastic component representing the other components that are unobservable to the researcher .

The probability of a "yes" answer we may be expressed as:

$P(Y e s)=P\left(A^{*} \geq A_{k}\right)$.

This response probability model may be estimated using parametric, seminonparametric and non-parametric methods. In the next sections, we explain the different approaches and how the effect of the age has been included. In this way we will test to what extent our results are influenced by the statistical assumptions of the models.

\subsection{Parametric approach}

Parametric methods introduce different distributional and functional assumptions upon the WTP function. We use a log-logistic model [4] because it fits the data better than other models. This model assumes that WTP is an exponential function of a linear combination of individual characteristics $\vec{x}$ and additive error term that follows a logistic distribution [10]. Therefore, individual willingness to pay for the improvement in the level of mortality risk will be non-negative, which is a desired feature for this study since the respondent should have non-negative preferences about reductions in risk mortality. The response probability function is specified as:

$P($ Yes $)=\frac{1}{1+\exp \left(-\left(\vec{x}^{\prime} \vec{\beta}+\alpha \ln \left(A_{k}\right)\right)\right.}$

Within this framework, the effect of age on individual's responses can be included in $\vec{x}$ using different specifications. Following to Krupnick [14], we use several specifications for the age variable, namely, linear, quadratic and two specifications for dummies.

\subsection{Semi-nonparametric approach}


An alternative procedure consists in semi-nonparametric methods [7]. They reduce the sensitivity of results to specific parametric assumptions about the form of the WTP distribution. This is achieved replacing the linear combination in the WTP function with a Fourier flexible form [9]. As a result, the models follow more closely the data and are less influenced by statistical assumptions. The probability is expressed as:

$$
P(\text { Yes })=\frac{1}{1+\exp \left(-\left[\alpha \ln \left(A_{k}\right)+\vec{x}^{\prime} \vec{\beta}+2 \sum_{m=1}^{M} \sum_{j=1}^{J}\left(v_{j m} \cos \left[j \vec{r}_{m}^{\prime} s(\vec{x})\right]+w_{j m} \sin \left[j \vec{r}_{m}, s(\vec{x})\right]\right)\right)\right.}
$$

where $\alpha, \vec{\beta}, \vec{v}_{j m}$ and $\vec{w}_{j m}$ denote the coefficients to be estimated, $M$ and $J$ are positive integers, $\vec{r}_{m}$ is a vector of positive and negative integers that form indices in the conditioning variables and specify which variables in $\vec{x}$ are combined to obtain the transformed variables, and the function $s(\vec{x})$ is a scaling function. This scaling function subtracts of each variable in $\vec{x}$ its minimum value and then divide by its maximum and, finally, multiply by $2 \pi-0.0001$. As a result, each scaled variable lies in the interval $[0,2 \pi-0.0001]$. This scaling process is needed to avoid periodicity in the model [9]. Following Creel and Loomis [7] and Cooper [6] quadratic terms are not included in the Fourier expression.

In this paper, the cos and sin transformations will be applied over the age variable, with the purpose of capturing non-linearities associated to this variable.

\subsection{Non-parametric approach}

Non-parametric methods have the advantage of avoiding statistical assumptions on the response probability function, as well as the simplicity of estimation. Consider $\mathrm{K}$ different bids, $\vec{A}=\left\{A_{1}, A_{2}, \ldots, A_{K}\right\}$ where $\mathrm{A}_{1}<\mathrm{A}_{2}<\ldots<\mathrm{A}_{\mathrm{K}}$. Bids are assigned to people from $\mathrm{K}$ subsamples of size $\mathrm{n}_{1}, \mathrm{n}_{2}, \ldots, \mathrm{n}_{\mathrm{K}}$, with $\sum_{k=1}^{K} n_{k}=N$ being the sample size. Let $\mathrm{d}_{\mathrm{k}}$ denote the number of people from subsample $A_{k}$ who accept the bid offer (or number of yes answers), i.e. those individuals with an actual WTP not lower than the bid. The 
proportion of yes answers to bid $\mathrm{A}_{\mathrm{k}}$ from subsample $\mathrm{n}_{\mathrm{k}}$ would then be $P_{k}=\frac{d_{k}}{n_{k}}$, and the sequence of affirmative answer proportions would be $\vec{P}=\left\{P_{1}, P_{2}, \ldots, P_{K}\right\}$.

A common assumption used in non-parametric estimation is that this sequence of proportions has to be monotonically non-increasing, and when the assumption is violated ( $P_{k}>P_{k-1}$ for any $\mathrm{k}$ ), the sequence is forced to be monotonic. In this sense, Ayer et al. [3] propose to replace the proportions $P_{k}$ and $P_{k-1}$ that violate monotonicity by $\hat{P}_{k}=\hat{P}_{k-1}=\frac{d_{k}+d_{k-1}}{n_{k}+n_{k-1}}$. If after that the sequence still violates monotonicity for other pairs of bids, the same procedure is repeated until the series becomes monotonic, i.e. until $\hat{P}_{1} \geq \hat{P}_{2} \geq \ldots \geq \hat{P}_{\mathrm{K}}$.

There are three basic ways to estimate non-parametrically the response probability function out of the monotonic sequence (see, for instance, [5]): the Paasche procedure, the Laspeyres procedure; and the intermedium one. The estimated value of the probability of acceptance of the offered bid, $\forall A \in\left[A_{k}, A_{k+1}\right)$, will be equal to:

$P(Y e s)=\hat{P}_{k}$ in the Paasche procedure, $P(Y e s)=\hat{P}_{k+1}$ in the Laspeyres procedure, $P($ Yes $)=\hat{P}_{k}+\frac{\left(\hat{P}_{k+1}-\hat{P}_{k}\right)}{\left(A_{k+1}-A_{k}\right)}\left(A-A_{k}\right)$ in the intermedium procedure, being this expression the line connecting the points $\left(A_{k}, \hat{P}_{k}\right)$ y $\left(A_{k+1}, \hat{P}_{k+1}\right)$.

From these procedures, Laspeyres is the most conservative and it is the method we will use. Moreover, this procedure does not require any assumption upon the upper distribution endpoint, that is, the value of $A_{K+1}$ that verifies $\hat{P}_{\mathrm{K}+1}=0$.

Non-parametric methods have some disadvantages as their relative inefficiency compared to a correctly specified parametric model, or the difficulty to include covariates in the analysis and include constraints in the estimation process $[11,12]$. 


\subsection{Mean WTP estimate: marginal and total effects}

In parametric and semi-nonparametric methods, mean WTP is estimated integrating the response probability function over the interval $\left[0, A_{K}\right]$. This maximum bid truncation is recommended by some authors because no information is available beyond that point $[4,10,23]$. In the case of non-parametric methods, mean WTP is estimated in a similar way, that is, calculating the area under the probability of acceptance curve in the interval $\left[0, \mathrm{~A}_{\mathrm{K}}\right]$ (Kaplan-Meier-Turnbull estimator, [24]).

Given these models we can estimate the senior discount using the marginal effect of age on WTP or using the total effect approach. Marginal effect will be estimated using parametric and semi-nonparametric models. In parametric models the way of testing for the existence of the senior discount will depend on the functional form used. If age is entered linearly, there will be a senior discount if age coefficient is negative; if we add a quadratic term the function will be inversely U-shaped having the maximum before old age; if age is entered as a dummy variable the coefficient for seniors is negative (assuming young people is the base category). In semi-nonparametric models it is not so simple to observe the existence for the senior discount. First, it is important to check that the coefficients of the cos and $\sin$ transformations are significant. If they are, it implies that the model is capturing non-linearities that are neglected by our parametric models. If they are, we need to estimate WTP conditional on age to test if the senior discount is observed.

Total effect implies estimating different WTP for each age group. We could also use parametric and semi-nonparametric models in this case. However, since total effect can be estimated without any parameterization we think it makes more sense to use nonparametric methods to apply this approach. In this way we avoid the problems observed by Alberini [1] and Robinson and Hammit [22] that were explained in the Introduction of this paper.

\subsection{Value of statistical life year (VSLY)}

The value of a statistical life year conditioned on age $\left(\mathrm{VSLY}_{\mathrm{A}}\right)$ will be computed as in Viscusi and Hersch [26], that is, 
$V S L Y_{A}=\frac{r\left(V S L_{A}\right)}{\left[1-(1+r)^{-L}\right]}$

where $\mathrm{VSL}_{\mathrm{A}}$ stands for the Value of Statistical Life at age A, $\mathrm{r}$ is the discount rate and $\mathrm{L}$ is the remaining life expectancy at age A. If VSL declines in the same proportion as life expectancy with people grew older, VSLY will be constant or independent of age. This is the usual assumption used in the literature. However, if VSL declines less than proportionally with life expectancy, VSLY will increase with age. We believe it is important to use our data to compute VSLY given the large amount of subjects older than 65 that we have in our sample (18.97\%). Estimations of VSLY based of revealed preferences often rely on data from the labour market and there are hardly observations of subjects older than 65. Also, databases that use stated preferences do not have usually enough observations of subjects older than 65 in order to make a distinction within this group. This is important since some policies specially benefit older seniors (75 and above). Some examples of those policies are, clean air policies (in the environmental area) or cancer drugs (in the health policy area). Viscusi and Hersch [26] (p.950) show that "the VSLY varies from youngest to oldest by a factor of three for men and a factor of two for women". However, by oldest they refer to those in the 55-64 range. It is important to know if the pattern follows for older cohorts.

\section{Results $^{2}$}

The number of subjects we finally used was 5566 and not 6024 as 458 chose the option "I don't know" in the WTP question. These 458 individuals were distributed between surveys and frames as follows: December $(n=61)$, February $(n=64)$, March $(n=98)$, April ( $n=127)$, May ( $n=108)$, EP1 ( $n=125)$, EP2 ( $n=139)$, EP3 ( $n=194)$. The distribution of the remaining 5566 individuals was: December ( $n=1146)$, February $(n=1145)$, March ( $n=1103)$, April ( $n=1079)$, May ( $n=1093)$, EP1 ( $n=2291)$, EP2 ( $=1458)$, EP3 ( $n=1817)$. No statistically significant differences among the samples were found [27].

More than $35 \%$ of subjects did not respond to the question of income level. In order not to lose those observations we looked for a proxy variable. Social Status performed very well since it is closely related to income. This is a Likert type scale of self perceived

\footnotetext{
${ }^{2}$ There is supplementary material, with more results, that is available upon request from the authors for the reader interested in more detailed information.
} 
Social Status. It goes from 0 -Lowest Social Status- to 8 -Highest Social Status-. The correlation between these two variables (Income and Social Status) was measured using the Gamma statistic, obtaining a value of 0.87 , close to 1 , the strongest level of association. In general, the sample was representative of the Spanish population and there were no differences in sociodemographic characteristics between the three framings used.

\subsection{Data quality}

\subsubsection{Sensitivity to irrelevant factors}

The different tests showed the lack of sensitivity of the responses to theoretically irrelevant factors $(p>0.1)$. The proportion of subjects choosing one alternative or the status quo was very similar in all contexts. No evidence of statistically significant framing effects or order effects was found. We did not observe statistically significant effects either when probabilities were presented as number of events in a group of 100 or 1000 subjects.

\subsubsection{Sensitivity to relevant factors}

The main "relevant factor" was the sensitivity of WTP to the size of the risk reduction. In order to test for scope effects estimates of mean WTP were obtained using the nonparametric Turnbull estimator. Mean WTP for a 3\% risk reduction was clearly higher in EP1 than the corresponding means for smaller risk reductions in group EP3 $(p<0.01)^{3}$. Also, there were not statistical significant differences $(p=0.11)$ between the $3 \%$ risk reduction in groups EP1 and EP3. Finally, the proxy variable for income was significant in the direction predicted by theory.

In summary, the data seem to behave quite well in terms of their relationship with theory. They are sensitive to things that should matter and not sensitive to things that should not matter. Given that the data are internally consistent we proceed to pool the responses obtained from the three elicitation procedures considered.

\section{2. Marginal Effect: parametric and semi-nonparametric models}

\footnotetext{
3 One-sided approximate significance level obtained following Poe et al. [21] with non-parametric bootstrapping and 10,000 replicates.
} 
The main results of the parametric and semi-nonparametric models can be seen in Figure 1 . The dependent variable is a binary choice variable that takes a value of 1 if the individual answered yes to the WTP question and 0 if the individual answered no. Together with age, we have included in these models several independent variables to capture the possible influence of other important factors on WTP, namely gender, level of education and income. Definitions of the variables are as follows. Gender is a binary variable where the value 1 means male and the value 0 represent the female category. Income and Education are two binary variables built from the variables Level of social status and Level of education, respectively. Income takes a value to 1 when the variable Level of social status is higher than 3. Education takes a value of 1 when Level of education is higher than lower secondary. The cutoff points were chosen to produce two different groups of approximately the same size in order to increase the statistical power of the tests in the total effect analysis. The coherence of the resulting subgroups was checked. Level of social status is assumed to be a proxy for income as explained above. The values of some of these covariates was not reported by 30 individuals, resulting a final sample size of 5536 individuals $(n=2279$ in EP1, $n=1449$ in EP2, and $n=1808$ in EP3).

The coefficient of age for the linear model is negative and statistically significant $(\mathrm{p}<0.05)$, suggesting lower WTP as age increases. The quadratic term is also statistically different from zero and negative so the function is inversely U-Shaped. Figure 1 shows that the function peaks at age 39 (Monthly WTP=942.9€). If we set up this value as 1 , the relative value for a 65 year old would be 0.87 and 0.70 for an 80 year old. The two models with dummies also provide a similar picture. In the case of the semi-nonparametric model, we have applied only the cos and sin transformations to the age variable, since these transformations were non-significant for the $\ln (\mathrm{bid})$ variable. The results for the semi-nonparametric model are very similar to the quadratic model except for the fact that the quadratic model seems to understate WTP for older seniors (over 75). In relation to sociodemographic variables, we obtain that Gender is not significant in any model while Education and Income are significant: subjects with higher income and higher education have higher WTP.

\subsection{Total effect: non-parametric models}


Results for the total effect non-parametric model can also be seen in Figure 1. These results basically confirm what we have observed in parametric and semi-nonparametric, namely, WTP has a concave relationship with age, with the maximum located at around 40 and continuously falling with age from that point. However, the non-parametric total effect model increases the senior discount, since WTP for subjects older than 60 is lower than what is predicted by any parametric or semi-nonparametric models. Now the 65 years old would have a WTP that is $67 \%$ (instead of $87 \%$ ) in relation to the subjects with highest WTP and 75 years old would have a WTP that is $62 \%$ in relation to the maximum WTP. However, it falls quite sharply for those who are over 80 that have a WTP that is only $36 \%$ of the maximum.

One of the limitations of the total effect approach is that it is difficult to disentangle the effect of the different variables that are correlated with age. In our case, given the large sample size, we can apply the total effect for more uniform groups. In Table II we see non-parametric WTP for Age-Education groups and for Age-Income groups. Tests for differences in mean WTP are reported in Table III. The senior discount is independent of the level of education but is not independent of the level of income, since it concentrates only on low-income subjects. Finally, we can even do finer categories (although sample size becomes dangerously small for some of them) (see Tables II and III). When we do this, we see that the senior discount is related more to the income level than to the education level. When income level is high, we do not observe any senior discount, independently of the education level. When income level is low, we observe the senior discount, independently of the education level.

\subsection{Value of Statistical Life Year}

The relationship between Age and VSLY can be seen in Figure 2. We can see that the relative values are very similar for men and women. We show the results for the semiparametric model but the rest of models provide a similar perspective. Our results are a little bit different to those obtained by Viscusi and Hersch [26]. We obtain a very similar ratio of the VSLY for men and for women while it is different for them. In their case, it was about 3 for men and about 2 for women. In our case, it is about 1.7 for men and 1.5 for women (60 years old vs 20 years old). However, we can see that this ratio accelerates around 65. This is not surprising given that WTP changes much less with 
age than life expectancy. The relative value of a life year for an 85 year old is about 3.5 higher than the corresponding value of a 20 year old.

\section{Concluding remarks}

We have presented in this paper what we believe is one of the more solid pieces of evidence on the existence of the senior discount. Most of the methodological problems that have been shown to affect the calculation of the senior discount do not apply to our paper. Of course, it does not mean that the paper is free from limitations. First, we have used a case study where risk reduction is much higher than the usual papers that have estimated the senior discount. In our case, we have been dealing with a health problem that is (more or less) familiar to most subjects and we have been using a 3\% risk reduction in mortality, far larger than most of the studies on the VSL where risk reductions are usually presented as $\mathrm{X}$ in 100,000 or in 10,000 . The study of Alberini et al. [2] presented risk reductions of 1 and 5 in 1000 and they are amongst the largest risk reductions we have seen in order to estimate VSL. For this reason, we think that the implicit VSL present in our data is not comparable to other studies and we have not computed any VSL in this paper. For all these reasons, one potential criticism to this paper is that the risk reduction we have studied is different from other studies, since it deals with higher risk reductions and they refer to a private good, while the senior discount is usually relevant in policies related to public goods that deal with smaller risk reductions. While all this can be true, it is also true that the fact that we used a health problem that is fairly well known by member of the general population, and the fact that we have used higher risks reductions may have contributed to collect data that are highly consistent. In that respect, the estimations of the senior discount may have been less affected by problems in dealing with unfamiliar goods and very small probabilities, as it happens in other studies. A second limitation is that, in order to achieve a large number of observations in a face-to-face survey, we needed to insert our study in a survey where people were asked about other issues. We accept that this is not the ideal way of conducted a Willingness to Pay study. However, we have tried to reduce the limitations of this methods is several ways. We had previous experience in the issue of risk reduction for AMI using in-depth face-to-face interviews. The visual aid and the framing of the questions were then fully piloted. We knew that most subjects did not need too much time to understand the main concept, namely, that after an AMI your risk of death increases and medicines can reduce this risk. In summary, in the trade-off 
between providing in-depth information and having a large sample size we clearly chose sample size and we try to compensate for that presenting a case study that subjects could grasp more or less easily and presenting risks reductions of a size that subjects can understand easily. A third limitation is that we used several framings so not all subjects were asked exactly the same type of questions. However, we observed similar results (not shown) when only the data from EP1 were used. Given the results of these checks, it does not seem that our results suggest a lack of understanding of the good being valued. There is nothing in the data to suggest this is the case.

The results show a remarkable consistency between methods. The problems that Alberini [1] observed in other databases are not present here. In our case, simple methods (e.g., a quadratic utility function) do not seem to be very different from the more sophisticated and flexible semi non-parametric approach. Also, the results of the non-parametric approach are in line with the rest of results, so they can hardly be attributed to statistical assumptions of the model. In addition to that, this is one of the few papers that has used the marginal and the total approach and the fact that both approaches produce similar results is another indication of a very stable pattern. Krupnick [14], talking about the senior discount, points out that "if an effect (or its absence) is not robust, then one can probably manipulate the data to find any desired outcome. Alberini's [1] manipulation of data from several of the studies suggests that these effects can come and go depending on unrelated or incidental analytical choices". This is not our case.

The pattern observed confirms the presence of the senior discount but our results also confirms that the size of this effect is limited. Krupnick [14] suggests that a discount of $25 \%$ may not be very relevant in order to use different VSL for seniors. In our case, the results are in this range. Also, the fact that this discount is mainly concentrated on lowincome subjects raises obvious ethical issues that make the application of this discount doubtful. However, this is not for us to say. It is true that the non-parametric results suggest a much larger discount for the oldest seniors (80 years and more). We have to be cautious about this result, since this is the group with lower number of observations. If this were considered a relevant issue, more evidence would be needed for people in that range. 
Finally, our results raise important issues in those areas that base their policies on the concept of Value of a Life Year or Quality-Adjusted Life Years (QALYs), for example, regulation of medicines. Those policies usually assume that the monetary value of a year of life or of a QALY is independent of age. Our results suggest that VSLY is not constant over the life cycle and that the monetary value of life years (or QALYs) increase with age.

\section{References}

1. Alberini A.: What is a life worth? Robustness of VSL values from contingent valuation surveys. Risk Analysis: An Official Publication of the Society for Risk Analysis 25(4), 783-800 (2005)

2. Alberini A., Cropper M., Krupnick A., Simon N.B.: Does the value of a statistical life vary with age and health status? Evidence from the US and Canada. Journal of Environmental Economics and Management 48(1), 769-792 (2004)

3. Ayer M., Brunk H.D., Ewing G.M., Reid W.T., Silverman E.: An empirical distribution function for sampling with incomplete information. Annals of Mathematical Statistics 26(4), 641-647 (1955)

4. Bishop R.C., Heberlein T.A.: Measuring values of extra-market goods: are indirect measures biased? American Journal of Agricultural Economics 61(5), 926-930 (1979)

5. Boman, M., Bostedt G., Kriström B.: Obtaining welfare bounds in discrete-response valuation studies: A non-parametric approach. Land Economics 75(2), 284-294 (1999) 
6. Cooper J.: Flexible functional form estimation of willingness to pay using dichotomous choice data. Journal of Environmental Economics and Management 43(2), $267-279(2002)$

7. Creel M., Loomis J.: Semi-nonparametric distribution-free dichotomous choice contingent valuation. Journal of Environmental Economics and Management 32(3), 341-358 (1997)

8. Cropper M., Hammitt J.K., Robinson L.A.: Valuing mortality risk reductions: Progress and challenges. Annual Review of Resource Economics 3, 311-333 (2011)

9. Gallant A.R.: Unbiased determination of production technologies. Journal of Econometrics 20, 285-323 (1982)

10. Hanemann, W.M., Kanninen, B.: The Statistical Analysis of Discrete-Response CV Data. In: Bateman I., Willis, K.G. (eds.) Valuing Environmental Preferences: Theory and Practice of the Contingent Valuation Method in the U.S, E.C. and Developing Countries, pp. 302-441. Oxford University Press, Oxford (1999)

11. Härdle W., Müller M., Sperlich S., Werwatz A.: Nonparametric and semiparametric models. An Introduction. Springer, New York (2004)

12. Horowitz J.L.: Semiparametric methods in econometrics. Springer, New York (1998)

13. Kriström B.: A Non-parametric Approach to the Estimation of Welfare Measures in Discrete Response Valuation Studies. Land Economics 66(2), 135-139 (1990)

14. Krupnick A.: Mortality-risk Valuation and Age: Stated Preference Evidence. Review of Environmental Economics and Policy 1(2), 261-282 (2007)

15. Loomes G.: (How) can we value health, safety and the environment? Journal of Economic Psychology 27(6), 713-736 (2006) 
16. McFadden D.: Contingent Valuation and Social Choice. American Journal of Agricultural Economics 76(4), 689-708 (1994)

17. McFadden D.: Computing Willingness to Pay in Random Utility Models. In: Moore J, Riezman R, Melvin J. (eds.) Trade, Theory and Econometrics: Essays in Honour of John S. Chipman. Routledge, London (1999)

18. Parducci A.: Category judgment: A range-frequency model. Psychological Review 72(6), 407-18 (1965)

19. Pinto-Prades J.L., Farreras V., Fernandez de Bobadilla J.: Willingness to pay for a reduction in mortality risk after a myocardial infarction: An application of the contingent valuation method to the case of eplerenone. European Journal of Health Economics 9(1), 69-78 (2008)

20. Pitt B., Remme W., Zannad F., Neaton J., Martinez F., Roniker B. Eplerenone, a selective aldosterone blocker, in patients with left ventricular dysfunction after myocardial infarction. New England Journal of Medicine 348(14), 1309-1321 (2003)

21. Poe G., Welsh M., Champ P.: Measuring the difference in mean willingness to pay when dichotomous choice contingent valuation responses are not independent. Land Econ 73(2), 255-267 (1997).

22. Robinson L.A., Hammitt J.K.: Valuing health and longevity in regulatory analysis: Current issues and challenges. Jerusalem Papers in Regulation \& Governance, Working Paper No. 4. (2010)

23. Sellar C., Chavas J.P., Stoll J.R.: Specification of the Logit Model: The Case of Valuation of Non-market Goods. Journal of Environental Econonomics and Management 13(4), 382-390 (1986)

24. Turnbull B.W.: The empirical distribution function with arbitrarily grouped, censored and truncated data. Journal of the Royal Statistical Society 38, 290-295 (1976) 
25. Viscusi W.K.: Policy challenges of the heterogeneity of the value of statistical life. Foundations and Trends ${ }^{\circledR}$ in Microeconomics 6(2), 99-172 (2010)

26. Viscusi W.K., Hersch J.: The mortality cost to smokers. Journal of Health Economics 27(4), 943-958 (2008)

27. Wang H.: Treatment of "Don't-Know" responses in contingent valuation surveys: a random valuation model. Journal of Environmental Economics and Management 32, 219-232 (1997).

Figure 1. WTP as a function of age using different specifications

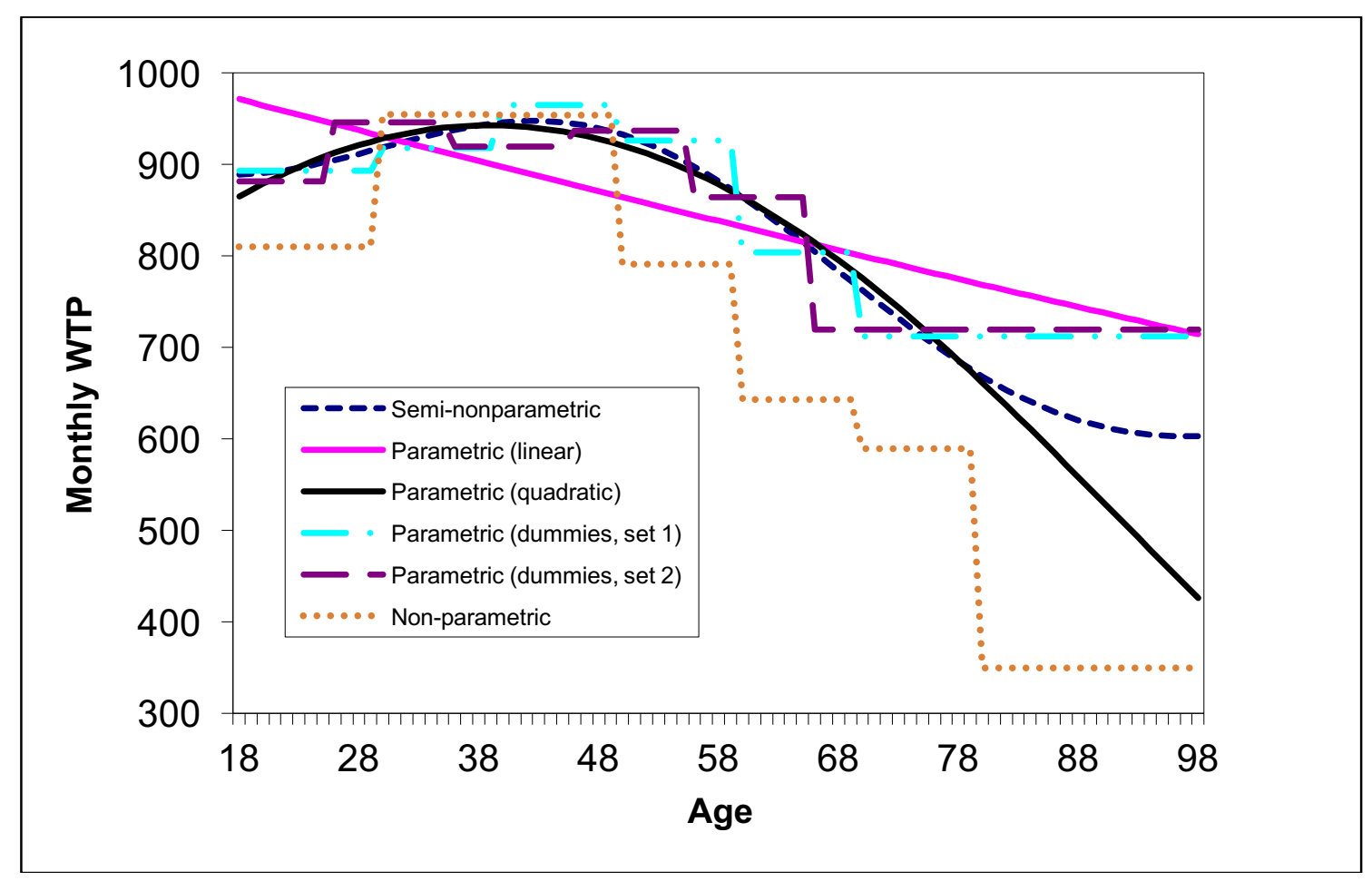

Figure 2. Relative value of a life year and age 


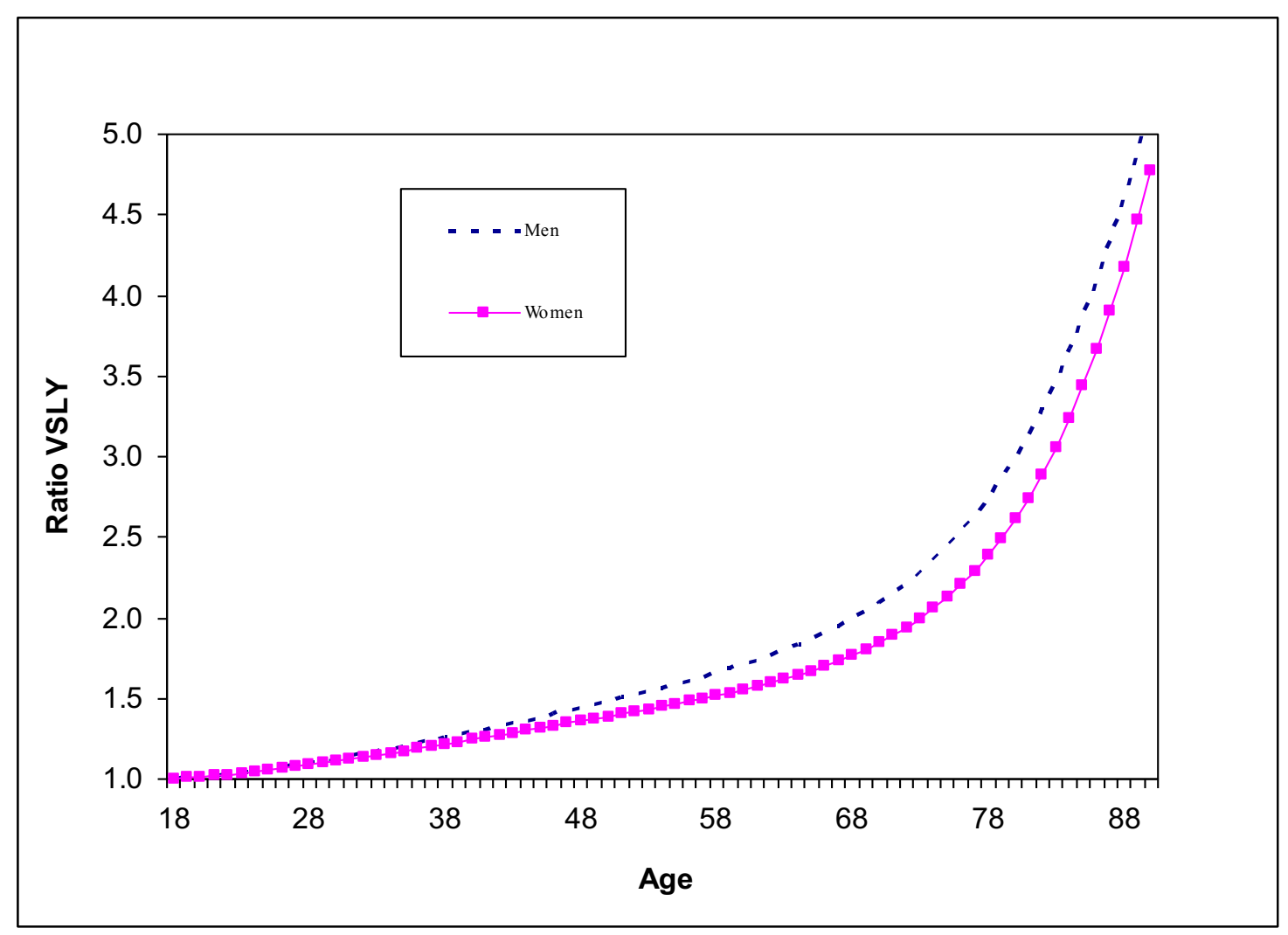

Table I. Options compared with status quo in the different elicitation procedures

\begin{tabular}{|c|c|c|c|c|c|c|c|c|c|}
\hline & \multirow[b]{2}{*}{ Group } & \multicolumn{2}{|c|}{$1^{\text {st }}$ question } & \multicolumn{2}{|c|}{$2^{\text {nd }}$ question } & \multicolumn{2}{|c|}{$3^{\text {rd }}$ question } & \multicolumn{2}{|c|}{$4^{\text {th }}$ question } \\
\hline & & $\begin{array}{c}\text { Risk } \\
\text { Reduction }\end{array}$ & Bid & $\begin{array}{c}\text { Risk } \\
\text { Reduction }\end{array}$ & $\mathrm{Bid}^{\mathrm{a}}$ & $\begin{array}{c}\text { Risk } \\
\text { Reduction }\end{array}$ & Bid & $\begin{array}{c}\text { Risk } \\
\text { Reduction }\end{array}$ & Bid \\
\hline \multirow{12}{*}{ EP1 } & 1 & $3 \%$ & 30 & $3 \%$ & $6 / 60$ & & & & \\
\hline & 2 & $3 \%$ & 60 & $3 \%$ & $30 / 90$ & & & & \\
\hline & 3 & $3 \%$ & 90 & $3 \%$ & $60 / 120$ & & & & \\
\hline & 4 & $3 \%$ & 120 & $3 \%$ & $90 / 240$ & & & & \\
\hline & 5 & $3 \%$ & 240 & $3 \%$ & $120 / 300$ & & & & \\
\hline & $6^{\mathrm{b}}$ & $3 \%$ & 90 & $3 \%$ & $60 / 120$ & & & & \\
\hline & 7 & $3 \%$ & 240 & $3 \%$ & $120 / 360$ & & & & \\
\hline & 8 & $3 \%$ & 480 & $3 \%$ & $360 / 720$ & & & & \\
\hline & 9 & $3 \%$ & 720 & $3 \%$ & $480 / 1080$ & & & & \\
\hline & 10 & $3 \%$ & 1080 & $3 \%$ & $720 / 1500$ & & & & \\
\hline & 11 & $3 \%$ & 1500 & $3 \%$ & $1080 / 2100$ & & & & \\
\hline & $12^{\mathrm{b}}$ & $3 \%$ & 720 & $3 \%$ & $480 / 1080$ & & & & \\
\hline \multirow{8}{*}{ EP2 } & 13 & $7 \%$ & 90 & $7 \%$ & 240 & $3 \%$ & 90 & $3 \%$ & 240 \\
\hline & 14 & $3 \%$ & 90 & $3 \%$ & 240 & $1 \%$ & 90 & $1 \%$ & 240 \\
\hline & 15 & $7 \%$ & 240 & $7 \%$ & 720 & $3 \%$ & 240 & $3 \%$ & 720 \\
\hline & 16 & $3 \%$ & 240 & $3 \%$ & 720 & $1 \%$ & 240 & $1 \%$ & 720 \\
\hline & 17 & $7 \%$ & 720 & $7 \%$ & 1500 & $3 \%$ & 720 & $3 \%$ & 1500 \\
\hline & 18 & $3 \%$ & 720 & $3 \%$ & 1500 & $1 \%$ & 720 & $1 \%$ & 1500 \\
\hline & 19 & $3 \%$ & 720 & $7 \%$ & 720 & $3 \%$ & 240 & $7 \%$ & 240 \\
\hline & 20 & $1 \%$ & 720 & $3 \%$ & 720 & $1 \%$ & 240 & $3 \%$ & 240 \\
\hline \multirow{3}{*}{ EP3 } & 21 & $1 \%$ & 240 & $5 \%$ & 240 & $1 \%$ & 240 & $3 \%$ & 240 \\
\hline & 22 & $3 \%$ & 240 & $1 \%$ & 240 & $5 \%$ & 240 & $1 \%$ & 240 \\
\hline & 23 & $1 \%$ & 720 & $3 \%$ & 720 & $5 \%$ & 720 & $7 \%$ & 720 \\
\hline
\end{tabular}




\begin{tabular}{|ccccccccc|}
\hline 24 & $7 \%$ & 720 & $5 \%$ & 720 & $3 \%$ & 720 & $1 \%$ & 720 \\
25 & $1 \%$ o & 30 & $5 \%$ o & 30 & $1 \%$ & 30 & $3 \%$ & 30 \\
26 & $1 \%$ o & 90 & $5 \%$ o & 90 & $1 \%$ & 90 & $3 \%$ & 90 \\
27 & $1 \%$ o & 720 & $5 \%$ o & 720 & $1 \%$ & 720 & $3 \%$ & 720 \\
28 & $1 \%$ o & 1500 & $5 \%$ o & 1500 & $1 \%$ & 1500 & $3 \%$ & 1500 \\
29 & $1 \%$ o & 2400 & $5 \%$ o & 2400 & $1 \%$ & 2400 & $3 \%$ & 2400 \\
30 & $1 \%$ & 240 & $3 \%$ & 240 & $5 \%$ & 240 & $7 \%$ & 240 \\
\hline
\end{tabular}

${ }^{a}$ For EP1, the step-down and step-up bids in the follow-up question are showed.

${ }^{\mathrm{b}}$ In groups 6 and 12 the change in risk was presented as a percentage (e.g. change in risk from $17 \%$ to $14 \%$ ) and not as number of events out of 1000 (from 170 to 140 out of 1000).

Table II. Turnbull estimates ${ }^{\text {a,b,c }}$

\begin{tabular}{|c|c|c|c|c|c|}
\hline Age & & Education $=0$ & Education $=1$ & Income $=0$ & Income $=1$ \\
\hline $18-39$ & $\begin{array}{l}\text { SS } \\
\text { WTP } \\
95 \% \text { CI }\end{array}$ & $\begin{array}{c}831 \\
\mathbf{7 6 7 . 2 2 3 1} \\
(619.7665 \\
889.9941)\end{array}$ & $\begin{array}{c}1553 \\
\mathbf{9 1 7 . 9 9 3 7} \\
(789.9550 \\
1048.6294)\end{array}$ & $\begin{array}{c}1024 \\
\mathbf{8 3 0 . 2 6 4 4} \\
(690.2903 \\
944.2519)\end{array}$ & $\begin{array}{c}1360 \\
\mathbf{9 2 1 . 7 9 9 6} \\
(764.3822, \\
1048.4235)\end{array}$ \\
\hline $40-59$ & $\begin{array}{l}\text { SS } \\
\text { WTP } \\
95 \% \text { CI }\end{array}$ & $\begin{array}{c}1019 \\
\mathbf{7 6 1 . 8 3 8 6} \\
(612.8578, \\
884.1717)\end{array}$ & $\begin{array}{c}597 \\
\mathbf{1 0 4 3 . 2 7 6 1} \\
(865.9058 \\
1200.9756)\end{array}$ & $\begin{array}{c}619 \\
\mathbf{8 1 1 . 5 7 4 2} \\
(632.7880, \\
956.9751)\end{array}$ & $\begin{array}{c}997 \\
\mathbf{9 1 1 . 2 0 4 5} \\
(766.4754, \\
1047.6154)\end{array}$ \\
\hline $60-98$ & $\begin{array}{l}\text { SS } \\
\text { WTP } \\
95 \% \text { CI }\end{array}$ & $\begin{array}{c}1355 \\
\mathbf{5 8 5 . 4 7 3 6} \\
(480.3164, \\
684.7205)\end{array}$ & $\begin{array}{c}181 \\
\mathbf{7 8 5 . 0 5 0 6} \\
(489.1202, \\
1021.9548)\end{array}$ & $\begin{array}{c}1328 \\
\mathbf{5 7 8 . 7 5 7 9} \\
(472.2253, \\
671.9622)\end{array}$ & $\begin{array}{c}208 \\
\mathbf{8 3 6 . 2 2 0 7} \\
(508.5941, \\
1085.4380)\end{array}$ \\
\hline & & $\begin{array}{c}\text { Education }=0 \\
\text { Income }=0\end{array}$ & $\begin{array}{c}\text { Education }=0 \\
\text { Income }=1\end{array}$ & $\begin{array}{c}\text { Education }=1 \\
\text { Income }=0\end{array}$ & $\begin{array}{c}\text { Education }=1 \\
\text { Income }=1\end{array}$ \\
\hline $18-39$ & $\begin{array}{l}\text { SS } \\
\text { WTP } \\
95 \% \text { CI }\end{array}$ & $\begin{array}{c}518 \\
\mathbf{7 5 0 . 0 2 7 8} \\
(567.5439 \\
893.8982) \\
\end{array}$ & $\begin{array}{c}313 \\
\mathbf{8 0 1 . 1 4 7 4} \\
(527.0013 \\
989.3712) \\
\end{array}$ & $\begin{array}{c}506 \\
\mathbf{9 0 0 . 7 0 2 7} \\
(695.6161 \\
1081.9317) \\
\end{array}$ & $\begin{array}{c}1047 \\
\mathbf{9 3 2 . 8 7 2 9} \\
(753.0156 \\
1090.9497) \\
\end{array}$ \\
\hline $40-59$ & SS & 544 & 475 & 75 & 522 \\
\hline
\end{tabular}




\begin{tabular}{|l|l|c|c|c|c|}
\hline & WTP & $\mathbf{7 7 5 . 0 6 7 5}$ & $\mathbf{7 2 0 . 5 4 4 7}$ & $\mathbf{9 6 7 . 8 0 9 5}$ & $\mathbf{1 0 3 0 . 8 2 9 5}$ \\
& & $(584.3483$, & $(502.5155$, & $(496.5085$, & $(844.9832$, \\
& $95 \%$ CI & $921.1827)$ & $918.0465)$ & $1282.2488)$ & $1215.7132)$ \\
\hline \multirow{3}{*}{$60-98$} & SS & 1247 & 108 & 81 & 100 \\
& WTP & $\mathbf{5 6 7 . 6 4 6 0}$ & $\mathbf{8 0 9 . 8 6 2 0}$ & $\mathbf{6 0 8 . 1 0 2 6}$ & $\mathbf{8 0 0 . 3 2 5 9}$ \\
& 95\% CI & $(461.5693$, & $(412.9454$, & $(435.4001$, & $(409.6608$, \\
& & $662.6024)$ & $1092.7710)$ & $751.8908)$ & $1193.8462)$ \\
\hline
\end{tabular}

${ }^{\mathrm{a}}$ Confidence interval estimated using non-parametric bootstrapping and 10,000 replicates.

${ }^{\mathrm{b}}$ Income $=1$ is the high income group. See main text for a more detailed definition.

${ }^{\mathrm{c}}$ Education=1 is the group with highest education level. See main text for a more detailed definition.

Table III. Hypothesis tests for differences betweeen WTP estimates for different profiles and age intervals ${ }^{\mathrm{a}, \mathrm{b}}$

\begin{tabular}{|c|c|c|c|c|}
\hline & Education $=0$ & Education $=1$ & Income $=0$ & Income $=1$ \\
\hline $\begin{array}{l}18-39 \text { vs } \\
40-59\end{array}$ & 0.4705 & 0.1411 & 0.4211 & 0.4880 \\
\hline $\begin{array}{l}18-39 \text { vs } \\
60-98\end{array}$ & 0.0205 & 0.1119 & 0.0009 & 0.2565 \\
\hline \multirow[t]{2}{*}{$\begin{array}{l}40-59 \text { vs } \\
60-98\end{array}$} & 0.0264 & 0.0352 & 0.0088 & 0.2555 \\
\hline & $\begin{array}{c}\text { Education }=0 \\
\text { Income }=0\end{array}$ & $\begin{array}{c}\text { Education }=0 \\
\text { Income }=1\end{array}$ & $\begin{array}{c}\text { Education }=1 \\
\text { Income }=0\end{array}$ & $\begin{array}{c}\text { Education }=1 \\
\text { Income }=1\end{array}$ \\
\hline $\begin{array}{l}18-39 \text { vs } \\
40-59\end{array}$ & 0.4163 & 0.3682 & 0.4854 & 0.2039 \\
\hline $\begin{array}{l}18-39 \text { vs } \\
60-98\end{array}$ & 0.0417 & 0.4289 & 0.0099 & 0.2297 \\
\hline $\begin{array}{l}40-59 \text { vs } \\
60-98\end{array}$ & 0.0269 & 0.4837 & 0.0872 & 0.1255 \\
\hline
\end{tabular}

${ }^{a}$ Age interval $\mathrm{i}$ is the interval with the higher WTP mean. 
${ }^{\mathrm{b}}$ One-sided approximate significance level obtained following Poe et al. [25] with non-parametric bootstrapping and 10,000 replicates.

\section{REVIEWERS' APPENDICES}

\section{APPENDIX 1: ANCILLARY ANALYSIS WITH THE RESPONSES TO DOUBLE- BOUND DICHOTOMOUS CHOICES}

As mentioned in the paper (footnote 1 and conclusions), similar conclusions were drawn when using only the response to the first bid in EP1, that is, for the Single-Bound Dichotomous questions. This appendix shows these results.

These WTP estimates are lower than those reported in the paper because the highest bid in the double-bounded exercise (EP1) is 1500€, while in the total sample $(\mathrm{EP} 1+\mathrm{EP} 2+\mathrm{EP} 3)$ is $2400 €$. As a consequence of that, the non-parametric estimate of the WTP is lower because the response probability model is truncated at a lower bid. In order to make comparisons between the parametric and non-parametric estimates, we have also truncated the parametric and semi-nonparametric estimates at $1500 €$. Anyway, we have also checked that using parametric models but truncating at $2400 €$ the same results as with the total sample are obtained. 
Figure 1bis. WTP as a function of age using different specifications

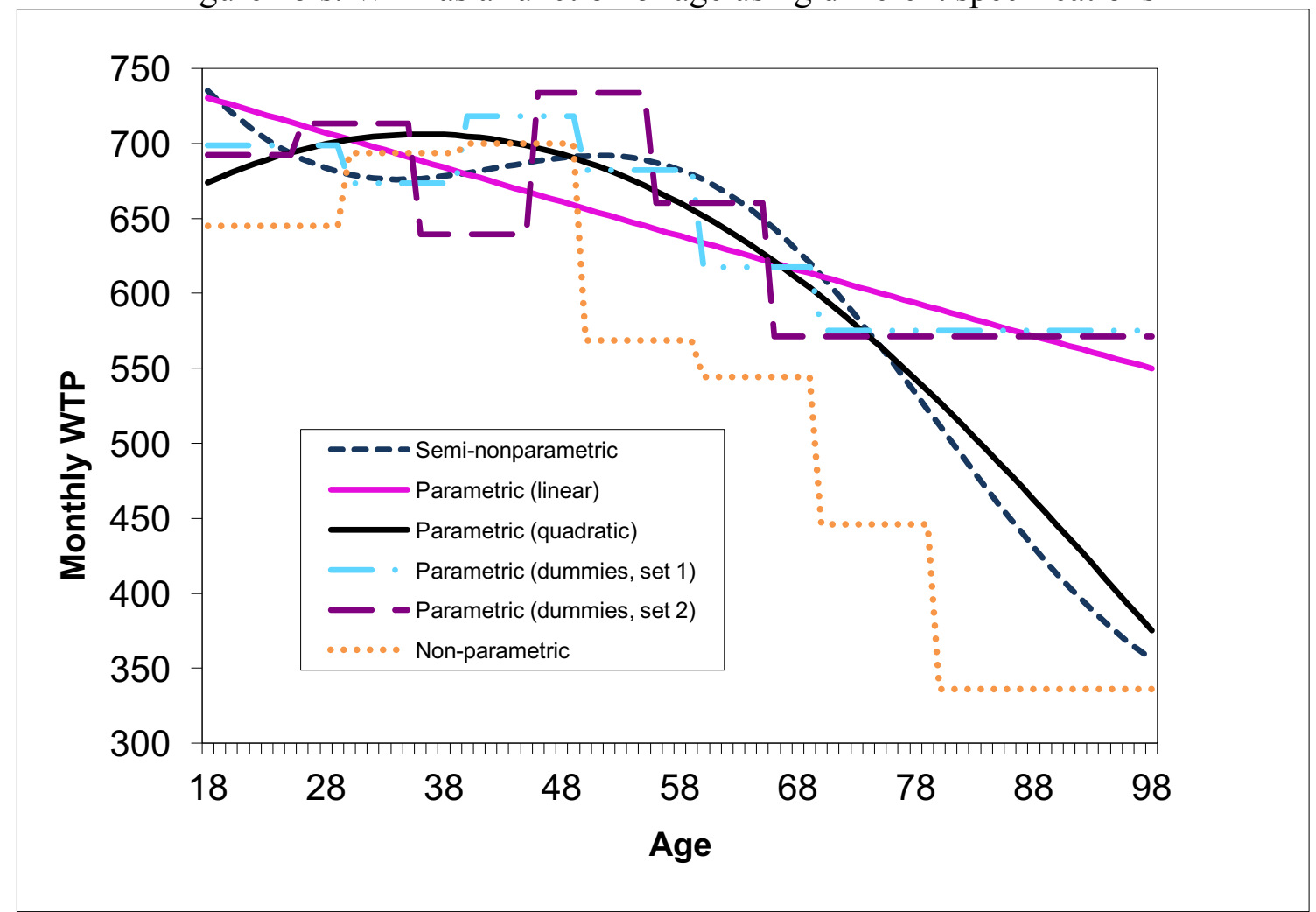

Table IIbis. Turnbull estimates ${ }^{\mathrm{a}}$

\begin{tabular}{|l|l|c|c|c|c|}
\hline & & Education=0 & Education=1 & Income $=0$ & Income $=1$ \\
\hline & SS & 351 & 646 & 409 & 588 \\
$\mathbf{1 8 - 3 9}$ & WTP & $\mathbf{6 4 3 . 9 7 9 1}$ & $\mathbf{6 7 8 . 8 9 6 0}$ & $\mathbf{6 1 4 . 9 1 7 1}$ & $\mathbf{7 1 9 . 8 4 0 1}$ \\
& & $(531.1475$, & $(603.7921$, & $(514.4614$, & $(631.2388$, \\
& $95 \%$ CI & $752.3979)$ & $756.7105)$ & $704.6930)$ & $795.8216)$ \\
\hline & SS & 409 & 234 & 243 & 400 \\
$\mathbf{4 0 - 5 9}$ & WTP & $\mathbf{5 7 3 . 4 9 6 3}$ & $\mathbf{7 2 2 . 6 6 4 3}$ & $\mathbf{5 1 7 . 6 2 1 2}$ & $\mathbf{6 7 8 . 6 1 6 9}$ \\
& 95\% CI & $(475.5795$, & $(574.0551$, & $(413.2745$, & $(575.4004$, \\
& $672.8780)$ & $847.0524)$ & $630.0686)$ & $784.1323)$ \\
\hline & SS & 565 & 74 & 553 & 86 \\
$\mathbf{6 0 - 9 8}$ & WTP & $\mathbf{4 8 2 . 2 6 5 0}$ & $\mathbf{6 3 0 . 6 3 6 7}$ & $\mathbf{4 9 0 . 8 5 3 3}$ & $\mathbf{5 6 2 . 5 7 5 8}$ \\
& 95\% CI & $(405.5720$, & $(429.5581$, & $(410.3216$, & $(371.1039$, \\
& & $558.5574)$ & $802.9437)$ & $567.9629)$ & $732.3772)$ \\
\hline
\end{tabular}

${ }^{a}$ Confidence interval estimated using non-parametric bootstrapping and 10,000 replicates.

Table IIIbis. Hypothesis tests for differences betweeen WTP estimates for different profiles and age intervals ${ }^{\mathrm{a}, \mathrm{b}}$

$\left(\mathrm{H}_{0}: \mathrm{WTP}_{\text {age interval i }}=\mathrm{WTP}_{\text {age interval } \mathrm{j}} ; \mathrm{H}_{1}: \mathrm{WTP}_{\text {age interval i }}>\mathrm{WTP}_{\text {age interval } \mathrm{j}}\right)$

\begin{tabular}{|c|c|c|c|c|}
\hline & Education $=0$ & Education $=1$ & Income $=0$ & Income $=1$ \\
\hline $\begin{array}{l}18-39 \text { vs } \\
40-59\end{array}$ & 0.1793 & 0.3417 & 0.1041 & 0.3096 \\
\hline
\end{tabular}




\begin{tabular}{|l|c|c|c|c|}
\hline $\begin{array}{l}18-39 \text { vs } \\
60-98\end{array}$ & 0.0090 & 0.2505 & 0.0275 & 0.0558 \\
\hline $\begin{array}{l}40-59 \text { vs } \\
60-98\end{array}$ & 0.0712 & 0.1936 & 0.3398 & 0.1146 \\
\hline
\end{tabular}

${ }^{\text {a }}$ Age interval $\mathrm{i}$ is the interval with the higher WTP mean.

${ }^{\mathrm{b}}$ One-sided approximate significance level obtained following Poe et al. [25] with non-parametric bootstrapping and 10,000 replicates.

All these estimates were obtained taking the highest bid in EP1 as the highest bid (that is, $1500 €)$. This way the parametric, semi-nonparametric and non-parametric estimates are comparable. In order to compare the WTP estimates obtained from the EP1 with those obtained from the total sample $(\mathrm{EP} 1+\mathrm{EP} 2+\mathrm{EP} 3)$, we re-estimate the WTP obtained from the EP1 with the linear specification for the variable age and we take as the highest bid for the truncation the highest bid in the total sample (that is, 2400€). The results are displayed in the following graph.

Figure 3. WTP as a function of age

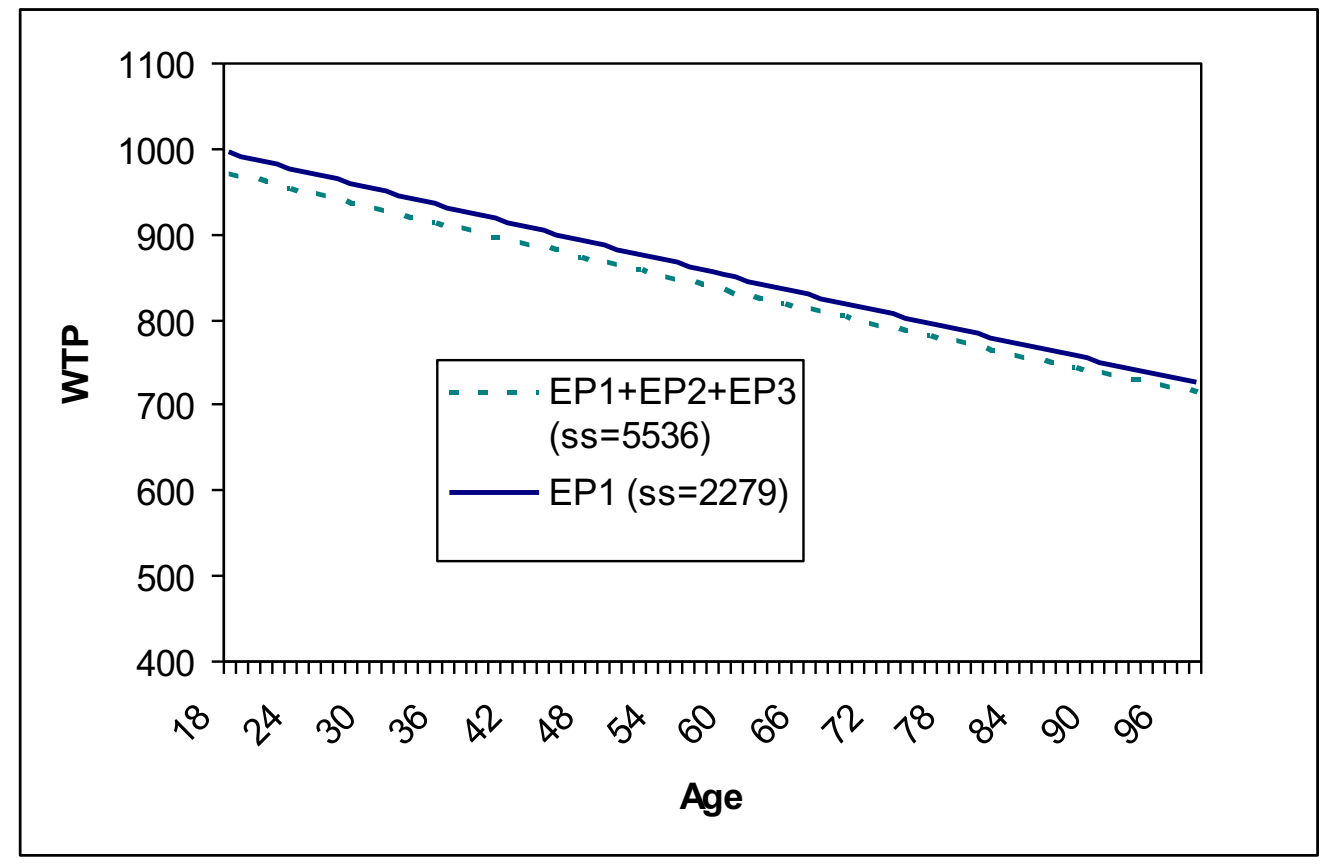




\section{APPENDIX 2: EXAMPLES OF SURVEY QUESTIONS}

\section{ELICITATION PROCEDURE 1}

We are going to talk now about medicines for a major problem like Acute Myocardial Infarction.

The acute myocardial infarction is a heart problem that usually occurs because fat builds up in the arteries that carry blood to the heart and they become clogged. Since there is not enough blood going to the heart, it does not receive enough oxygen and that part of the heart does not get the oxygen dies and the heart may stop working.

Occasionally, acute myocardial infarction results in immediate death. In other cases, the person survives but in the most severe cases, the heart and is permanently damaged. Because of this, these people have to take medicines after the infarction. Let us say they have to take medicine X. Despite taking medicine X, 170 out of 1000 people who have suffered a severe infarction and who have not died immediately will die the first year after having the infarction. After the first year, very few die from heart problems related to the Infarction. 
Suppose you just had a severe infarction and you have to take medicine $\mathrm{X}$ for one year. With such medication your risk of death the first year after infarction is 170 out of 1000 .

\section{[INTERVIEWER SHOW VISUAL AID 1]}

Suppose now that a new drug (say medicine A) is discovered for patients who had an infarction. Studies have shown that, if taken over a year after infarction, it reduces mortality from 170 to 140 per thousand. That is, 30 fewer people will die out of 1000 if the 1000 take drug $\mathrm{A}$ instead of $\mathrm{X}$.

\section{[INTERVIEWER SHOW VISUAL AID 2]}

The new medicine A does not add any new side effect to the usual treatment with medicine $\mathrm{X}$.

Assume that medicine $\mathrm{X}$ does not generate any extra cost to your monthly expenditures. Taking medicine $\mathrm{X}$ does not generate additional expenditures. However, if you decide to take medicine A, your monthly expenditures will increase in $30 €$ for one year, that you will not be able to spend in other things.

In summary, you have two options:

- Take medicine $\mathrm{X}$ that does not increase your monthly expenditures and assume a risk of 170 in 1000.

- Take medicine A that will reduce your risk but that will cost you some money.

\section{[INTERVIEWER SHOW CARD 1]}

QUESTION 1. Please, let us know which of the next two options you would choose. 
I would not take medicine A, I would go for $\mathrm{X}_{\text {, }}$

so:

- I would accept a risk of death for the first year of $\mathbf{1 7 0}$ out of 1000 .

- No extra costs on medicines. $\underline{\text { Yes, I would take medicine A, so: }}$

- I would accept a risk of death for the first year of

140 out of 1000 , that is, $\underline{\mathbf{3 0} \text { less out of } \mathbf{1 0 0 0}}$.

- My monthly expenses in medicines would increase in $30 €$.

a. I would not take the medicine $\rightarrow$ go to question 2

b. I would not take the medicine $\rightarrow$ go to question 3

\section{QUESTION 2}

Assume that the cost of the medicine is smaller, instead of $30 €$ per month, you would have to pay $6 €$ per month for 1 year. Would you pay $6 €$ per month for medicine A?

\section{QUESTION 3}

Assume that the cost of the medicine is higher, instead of $30 €$ per month, you would have to pay $60 €$ per month for 1 year. Would you pay $60 €$ per month for medicine A?

\section{ELICITATION PROCEDURE 2}

We are going to talk now about medicines for a major problem like Acute Myocardial Infarction.

The acute myocardial infarction is a heart problem that usually occurs because fat builds up in the arteries that carry blood to the heart and they become clogged. Since there is not enough blood going to the heart, it does not receive enough oxygen and that part of the heart does not get the oxygen dies and the heart may stop working.

Occasionally, acute myocardial infarction results in immediate death. In other cases, the person survives but in the most severe cases, the heart and is permanently damaged. Because of this, these people have to take medicines after the infarction. Let us say they have to take medicine X. Despite taking medicine X, 170 out of 1000 people who have 
suffered a severe infarction and who have not died immediately will die the first year after having the infarction. After the first year, very few die from heart problems related to the Infarction.

Suppose you just had a severe infarction and you have to take medicine $\mathrm{X}$ for one year. With such medication your risk of death the first year after infarction is 170 out of 1000 .

[INTERVIEWER SHOW VISUAL AID 1]

Suppose now that a new drug (say medicine A) is discovered for patients who had an infarction. Studies have shown that, if taken over a year after infarction, it reduces mortality but it does not have the same effect in all patients.

- In one group (group 1) medicine A reduce mortality from 170 to 140 per thousand. That is, 30 fewer people will die out of 1000 if the 1000 take drug A instead of X. [INTERVIEWER SHOW VISUAL AID 2]

- In one group (group 2) medicine A reduce mortality from 170 to 100 per thousand. That is, 70 fewer people will die out of 1000 if the 1000 take drug A instead of X. [INTERVIEWER SHOW VISUAL AID 3]

There is a medical test that can tell you if you belong to group 1 or 2 .

The new medicine A does not add any new side effect to the usual treatment with medicine $\mathrm{X}$.

Assume that medicine $\mathrm{X}$ does not generate any extra cost to your monthly expenditures. Taking medicine $\mathrm{X}$ does not generate additional expenditures. However, if you decide to take medicine A, your monthly expenditures will increase. Since the drug is very new, we do not know the price exactly. All we know is that will generate extra costs to you in medicines that will move between a minimum of $90 €$ per month for one year and a maximum of $240 €$ per year.

In summary, you have two options:

- Take medicine $X$ that does not increase your monthly expenditures and you accept a risk of death of 170 in 1000 . 
- Take medicine A that will reduce your risk but that will cost you some money.

Before deciding if it is better option 1 or 2 you have to think that there are, at least, four potential situations:

1. The medical test tells you that you belong to group 2. Medicine A will reduce your risk from 170 to 100 in 1000 . The cost for you is $90 €$ per month.

2. The medical test tells you that you belong to group 2. Medicine A will reduce your risk from 170 to 100 in 1000 . The cost for you is $240 €$ per month.

3. The medical test tells you that you belong to group 1. Medicine A will reduce your risk from 170 to 140 in 1000 . The cost for you is $90 €$ per month.

4. The medical test tells you that you belong to group 1. Medicine A will reduce your risk from 170 to 140 in 1000 . The cost for you is $240 €$ per month..

We are going to ask you if you think you would choose medicine A or X in each case.

[INTERVIEWER: THE SUBJECT HAS TO RESPOND TO NEXT QUESTIONS WITH THE NEXT SHEET IN FRONT OF HIM/HER. THE SUBJECT MUST HAVE THE FOUR CASES IN FRONT OF HIM/HER EVENTHOUGH RESPONDS TO EACH QUESTION INDIVIDUALLY]

[INTERVIEWER: THE SUBJECT HAS TO BE ABLE TO SEE VISUAL AID 2 AND 3 WHILE RESPONDING TO NEXT QUESTIONS]

Case 1. The medical test tells you that you belong to group 2. Medicine A will reduce your risk from 170 to 100 in 1000 . The cost for you is $90 €$ per month.

I would not take medicine A, I would go for X, so

- I would accept a risk of death for the first year of 170 out of 1000 .

- No extra costs on medicines.
Yes, I would take medicine A, so:

- I would accept a risk of death for the first year of 100 out of 1000 , that is, $\mathbf{7 0}$ less out of 1000.

- My monthly expenses in medicines would increase in $90 €$.

Case 2. The medical test tells you that you belong to group 2. Medicine A will reduce your risk from 170 to 100 in 1000 . The cost for you is $240 €$ per month.

Yes, I would take medicine A, so:

- I would accept a risk of death for the first

- I would accept a risk of death for the first 


\begin{tabular}{|l|l|}
\hline year of $\mathbf{1 7 0}$ out of 1000. & $\begin{array}{l}\text { year of } \mathbf{1 0 0} \text { out of } 1000, \text { that is, } \underline{\mathbf{7 0} \text { less out of }} \\
\mathbf{1 0 0 0} .\end{array}$ \\
- No extra costs on medicines. & $\begin{array}{l}\text { My monthly expenses in medicines would } \\
\text { increase in } 240 € .\end{array}$ \\
\hline
\end{tabular}

Case 3. The medical test tells you that you belong to group 1. Medicine A will reduce your risk from 170 to 140 in 1000 . The cost for you is $90 €$ per month.

\begin{tabular}{|l|l|}
\hline I would not take medicine A, I would go for X so: & Yes, I would take medicine A, so: \\
- I would accept a risk of death for the first & - I would accept a risk of death for the first \\
year of $\mathbf{1 7 0}$ out of 1000. & $\begin{array}{l}\mathbf{1 0 0 0} . \\
\text { - No extra costs on medicines. }\end{array}$ \\
& $\begin{array}{l}\text { My monthly expenses in medicines would } \\
\text { increase in } \mathbf{9 0 €} .\end{array}$ \\
\hline
\end{tabular}

Case 4. The medical test tells you that you belong to group 1. Medicine A will reduce your risk from 170 to 140 in 1000 . The cost for you is $240 €$ per month.

I would not take medicine A, I would go for X so:

- I would accept a risk of death for the first year of 170 out of 1000 .

- No extra costs on medicines.
Yes, I would take medicine A, so:

- I would accept a risk of death for the first year of 140 out of 1000 , that is, $\underline{30}$ less out of $\underline{1000}$.

- My monthly expenses in medicines would increase in $240 €$.

\section{ELICITATION PROCEDURE 3}

We are going to talk now about medicines for a major problem like Acute Myocardial Infarction.

The acute myocardial infarction is a heart problem that usually occurs because fat builds up in the arteries that carry blood to the heart and they become clogged. Since there is not enough blood going to the heart, it does not receive enough oxygen and that part of the heart does not get the oxygen dies and the heart may stop working.

Occasionally, acute myocardial infarction results in immediate death. In other cases, the person survives but in the most severe cases, the heart and is permanently damaged. Because of this, these people have to take medicines after the infarction. Let us say they have to take medicine X. Despite taking medicine X, 170 out of 1000 people who have 
suffered a severe infarction and who have not died immediately will die the first year after having the infarction. After the first year, very few die from heart problems related to the Infarction.

Suppose you just had a severe infarction and you have to take medicine $\mathrm{X}$ for one year. With such medication your risk of death the first year after infarction is 170 out of 1000 . [INTERVIEWER SHOW VISUAL AID 1]

Suppose now that a new drug (say medicine A) is discovered for patients who had an infarction. Studies have shown that, if taken over a year after infarction, it reduces mortality but it does not have the same effect in all patients.

- In one group (group 1) medicine A reduce mortality from 170 to 169 per thousand. That is, 1 fewer person will die out of 1000 if the 1000 take drug A instead of X. [INTERVIEWER SHOW VISUAL AID 2]

- In one group (group 2) medicine A reduce mortality from 170 to 165 per thousand. That is, 5 fewer people will die out of 1000 if the 1000 take drug A instead of X. [INTERVIEWER SHOW VISUAL AID 3]

- In one group (group 3) medicine A reduce mortality from 170 to 160 per thousand. That is, 10 fewer person will die out of 1000 if the 1000 take drug A instead of X. [INTERVIEWER SHOW VISUAL AID 4]

- In one group (group 4) medicine A reduce mortality from 170 to 140 per thousand. That is, 30 fewer people will die out of 1000 if the 1000 take drug A instead of X. [INTERVIEWER SHOW VISUAL AID 5]

There is a medical test that can tell you the group you belong to.

The new medicine A does not add any new side effect to the usual treatment with medicine $X$.

Assume that medicine $\mathrm{X}$ does not generate any extra cost to your monthly expenditures. Taking medicine $\mathrm{X}$ does not generate additional expenditures. However, if you decide 
to take medicine A, your monthly expenditures will increase in $30 €$ for one year, that you will not be able to spend in other things.

In summary, you have two options:

- Take medicine $X$ that does not increase your monthly expenditures and you accept a risk of death of 170 in 1000 .

- Take medicine A that will reduce your risk but that will cost you some money.

Before deciding if it is better option 1 or 2 you have to think that there are, at least, four potential situations.:

1. The medical test tells you that you belong to group 1. Medicine A will reduce your risk from 170 to 169 in 1000 . The cost for you is $30 €$ per month.

2. The medical test tells you that you belong to group 2. Medicine A will reduce your risk from 170 to 165 in 1000 . The cost for you is $30 €$ per month.

3. The medical test tells you that you belong to group 3. Medicine A will reduce your risk from 170 to 160 in 1000 . The cost for you is $30 €$ per month.

4. The medical test tells you that you belong to group 4. Medicine A will reduce your risk from 170 to 140 in 1000 . The cost for you is $30 €$ per month..

We are going to ask you if you think you would choose medicine A or X in each case.

[INTERVIEWER: THE SUBJECT HAS TO RESPOND TO NEXT QUESTIONS WITH THE NEXT SHET IN FRONT OF HIM/HER. THE SUBJECT MUST HAVE THE FOUR CASES IN FRONT OF HIM/HER EVENTHOUGH RESPONDS TO EACH QUESTION]

[INTERVIEWER: THE SUBJECT HAS TO BE ABLE TO SEE VISUAL AID 1 WHILE RESPONDING TO NEXT QUESTIONS]

Case 1. The medical test tells you that you belong to group 1. Medicine A will reduce your risk from 170 to 169 in 1000 . The cost for you is $30 €$ per month.

$\underline{\text { I would not take medicine A, I would go for X, so }} \quad \underline{\text { Yes, I would take medicine A, so: }}$

- I would accept a risk of death for the first

- I would accept a risk of death for the first year of 170 out of 1000 . year of 169 out of 1000, that is, 1 less out of 1000. 
- No extra costs on medicines.

Case 2. The medical test tells you that you belong to group 2. Medicine A will reduce your risk from 170 to 165 in 1000 . The cost for you is $30 €$ per month.

I would not take medicine A, I would go for X so:

- I would accept a risk of death for the first year of 170 out of 1000 .

- No extra costs on medicines.

Case 3. The medical test tells you that you belong to group 3. Medicine A will reduce your risk from 170 to 160 in 1000 . The cost for you is $30 €$ per month.

I would not take medicine A, I would go for X so:

- I would accept a risk of death for the first year of 170 out of 1000 .

- No extra costs on medicines.

Yes, I would take medicine A, so:

- I would accept a risk of death for the first year of 160 out of 1000 , that is, 10 less out of 1000.

- My monthly expenses in medicines would increase in $30 €$.

Case 4. The medical test tells you that you belong to group 4. Medicine A will reduce your risk from 170 to 140 in 1000 . The cost for you is $30 €$ per month.

I would not take medicine A, I would go for X so:

- I would accept a risk of death for the first year of 170 out of 1000 .

- No extra costs on medicines. $\underline{\text { Yes, I would take medicine A, so: }}$

- I would accept a risk of death for the first year of 140 out of 1000 , that is, $\underline{30 \text { less out of }}$ $\underline{1000}$.

- My monthly expenses in medicines would increase in $30 €$. 